\title{
MERGERS \& ACQUISITIONS IN THE ELEVATOR INDUSTRY: THE USE OF ICTs TO AVOID INFORMATION ASYMMETRY
}

\author{
Juan de la Guardia ${ }^{1}$, Miguel Palacios ${ }^{2}$, and Ricardo Zurdo ${ }^{1}$ \\ ${ }^{1}$ Universidad San Pablo CEU \\ ${ }^{2}$ ESCP Business School - Madrid Campus
}

December 18, 2021

\begin{abstract}
Mergers and acquisitions operations continue to be one of the most explored growth strategies in all markets, and this is indeed the case in the elevator industry. The volume of investments grows year after year. It is the fastest way to grow in international and domestic markets, but the reality is that a high percentage of the operations carried out do not meet the expectations of the investors once the integration phase has been completed. There are several causes of failures in mergers and acquisitions processes, such as lack of commitment from the management, an unrealistic business plan, cultural shock, etc. But the most common one, and the one with the highest risk in an acquisition decision, is information asymmetry. During the negotiation phase a large amount of data is collected, and subsequently analyzed during the due diligence period, but it may not correspond to the reality during the integration phase. In this article we will propose how information asymmetry can be avoided through the application of information and communication technologies (ICTs) via internet of things (hereinafter IoT) devices in the elevator industry. This can also be applied to other industries.
\end{abstract}

MERGERS \& ACQUISITIONS IN THE ELEVATOR INDUSTRY: THE USE OF ICTs TO AVOID INFORMATION ASYMMETRY

Corresponding Author:

Juan de la Guardia García-Lomas

juan.dlg@hotmail.com

PhD Student at CEINDO

Universidad CEU San Pablo

CEU Universities

PhD Miguel Palacios.

Associate Dean Executive Education.

ESCP Business School

PhD Ricardo Palomo Zurdo

Dean

Professor of Finance

School of Business and Economics

Universidad CEU San Pablo 


\section{CEU Universities}

\section{ABSTRACT}

Mergers and acquisitions operations continue to be one of the most explored growth strategies in all markets, and this is indeed the case in the elevator industry. The volume of investments grows year after year. It is the fastest way to grow in international and domestic markets, but the reality is that a high percentage of the operations carried out do not meet the expectations of the investors once the integration phase has been completed. There are several causes of failures in mergers and acquisitions processes, such as lack of commitment from the management, an unrealistic business plan, cultural shock, etc. But the most common one, and the one with the highest risk in an acquisition decision, is information asymmetry. During the negotiation phase a large amount of data is collected, and subsequently analyzed during the due diligence period, but it may not correspond to the reality during the integration phase. In this article we will propose how information asymmetry can be avoided through the application of information and communication technologies (ICTs) via internet of things (hereinafter IoT) devices in the elevator industry. This can also be applied to other industries.

Keywords : IoT, IT Due Diligence, ICTs, Digital Strategy, Information Asymmetry, Adverse Selection, M\&A Performance, M\&A Success.

\section{INTRODUCTION}

In the elevator industry, there has historically been a great deal of mergers and acquisitions (hereinafter M\&A) activity between companies of different sizes, with the aim of accelerating strategic growth in certain international markets, or just in domestic markets. The aim is to become present in areas where the buyer's presence is low or non-existent. The operations consist of the purchase of a company that has maintenance service contracts for elevators, or simply the purchase of the portfolio of maintenance service contracts for said elevators.

These M\&A processes between elevator maintenance service companies are led by multinational manufacturing companies. As a rule, the candidates for acquisition are multibrand local companies, servicing different brands of elevators manufactured by multinationals, which for the most part still work without a defined digital strategy and with a much simpler quality management system than multinational companies. They use incomplete or poor procedures, with a work methodology based on experience, such as: "This is how we have always done it," which is not sufficient for obtaining, processing, and subsequently analyzing data. In M\&A processes between elevator maintenance companies of different sizes, the calculations and premises used by multinational companies to evaluate suitable candidates for acquisition are based on experiences and Excel-type spreadsheets. The data provided by the selected candidate may differ from the reality, meaning that M\&A projects that appeared beneficial in the pre-acquisition phase may result in failure in the integration phase, damaging the profit \& loss accounts (hereinafter P\&L) and the brand value of the purchasing company. In other words, the decision is based on subjective criteria that cause an overestimation of returns and an incorrect business plan due to asymmetric information that does not correspond to the reality (Akerlof 2001).

Why is there asymmetric information? Because the data used for the analysis and business case study in the pre-acquisition stage have not been obtained, treated, and processed correctly due to the seller's simple digital tools. When an M\&A operation takes place between different sized elevator maintenance companies that have different digital strategies, information asymmetry is the biggest cause of failure.

\section{BACKGROUND}

Currently, mergers and acquisitions processes are growing significantly around the world (Cartwright \& Schoenberg 2006). For example, in 2004 there were 30,000 M\&A operations around the world, equivalent to 1 operation every 18 minutes. However, despite the growth this entails, investors continue to experience low returns in the months following integration. For investors, the return on investment is still highly questionable. 
Authors who investigate the factors that motivate M\&A operations (Calipha, Tarba, \& Brock 2010) have found that the success rate of M\&A operations is below $50 \%$. The factors that motivate M\&A operations can include, among others, the entry into new markets, the acquisition of resources and talent, or simply the application of synergies. In a survey (Accenture and Economist Intelligence Unit 2006) conducted with executives of companies involved in M\&A operations, the following responses were obtained: $47 \%$ answered that the causes of failure come from the coordination and integration of the process; $43 \%$ responded that they come from the execution of due diligence (hereinafter DD); and $40 \%$ responded that the causes of failure were due to lack of motivation of the organization and lack of business cultural integration. An argument commonly used to explain failures in M\&A operations is that too much attention is paid to financial parameters and not enough to business and human organization, as well as operational parameters.

The DD process must resolve all doubts and questions during the pre-acquisition phase. Continuing with unresolved doubts and uncertainties can be critical during the integration phase. When different information appears in the integration or post-acquisition phase, this is what is called information asymmetry. Therefore, resolving ambiguity in the DD process is a success factor.

Information asymmetry is linked to the risk of the buyer paying over the odds. In an M\&A process there may be a potential "lemon" problem (Akerlof 2001) that can generate costs. According to Akerlof, asymmetric information exists when the seller has more information than the buyer. The seller can hide part of the information to avoid the risk of reduction of the offer prices by the buyer. During the negotiation phase (Dierickx 1991), the problem already appears when the seller cannot or does not want to transmit certain information to the buyer, so the buyer does not have all the real information. Cuypers, Cuypers, and Martin (2017) carried out an investigation on 1,241 articles over a 30-year period, and they argue that the party that obtains greater value in an M\&A process is the one with the most experience and that obtained the most information.

When considering and comparing, for example, the valuation of tangible products, information asymmetry also plays a relevant role. In a study carried out by Afzal, Roland, and al-Squri (2009), for two different groups of people, one of them receiving symmetric information on a product, and the other receiving asymmetric information on the same product, different valuations were obtained. The valuation closest to the real worth of the product was made by the group that received symmetric information.

When M\&A operations aim to penetrate international markets, the cost of the operation is still much higher due to information asymmetry. Boeh (2011) carried out a study of 3,000 M\&A operations and recreated a theoretical information asymmetry reduction model based on the hiring of a consultancy firm for the management and coordination of the M\&A operation. Some reduction mechanisms have been proposed.

Reuer and Akerlof (2005) propose three methods to resolve information asymmetry: selecting a different purchase structure, entering into a contractual agreement, and using information from other markets. Reuer and Ragozzino (2008) propose reducing information asymmetry through prior alliances and through an early interaction between seller and buyer. In a study carried out in Israel on startup acquisitions by two ICT companies, Brueller and Capron (2021) note that this early interaction comprises three phases (the " 3 Cs"): a first phase in which the seller has to be Complementary to the buyer, since buyers are generally defensive of their core business; a second phase involving key Customers who validate the operation; and a third and final phase, using executive Champions who sponsor the transaction.

Obtaining information is expensive. Nayyar (1990) points out that information asymmetry is usually the biggest source of costs for both parties: seller and buyer. There are alternatives to tackle the costs of information asymmetry, such as including responsibilities, guarantees, signaling in contracts, etc. But they are usually not sufficient or satisfactory. In fact, in some companies there is a specific function to improve the performance of M\&A operations, since capacities can be developed through lessons learned (Trichterborn, Zu Knyphausen, \& Schweizer 2016). More and more companies that are active in M\&A processes incorporate departments that are responsible for the valuation of the possible acquisition.

When an investor decides to acquire a company, a general strategy is always defined, but a specific strategy 
for IT integration is often not defined. Digital strategy disparity can have an impact on return on investment and on integration effectiveness in the post-acquisition phase. Sundberg, Tan, Baublits, Lee, Stanis, and Tanriverdi (2006) refer to a study by Accenture Consulting on IT integration in 57 acquisitions between 1997 and 1999: $42 \%$ did not carry out DD in IT, and the consequence was that the acquisitions did not produce the expected returns. In the elevator industry, this situation also occurs when the two companies have different digital strategies.

With the recent development of digital technology and the large amount of data recorded by devices, companies are increasingly driving digital transformation to create value. Value creation can only come when strategy formulation and strategy implementation are connected (Correani, Massis, Frattini, Messeni, \& Natalicchio 2020)

However, small and medium-sized enterprises (hereinafter SMEs), susceptible to being bought, do not invest in technological resources, and do not have ICTs to manage their maintenance portfolio and their clients. In many cases, the information is processed in simple Excel spreadsheets and manual databases. SMEs are still at an intermediate level of digitization compared to Industry 4.0 (Pirola, Cimini, \& Pinto 2019). All companies have the need to exploit the opportunity that digitization offers, so that they can use the data collected to increase knowledge and improve decision-making. Profitability is not only achieved through the experience and talent of people, but also through the collection and processing of information through technologies and processes such as big data in order to make correct decisions. Information processing, internal and external, is necessary for any efficient growth strategy, such as expanding into new markets or new business opportunities (García-Canal, Rialp-Criado, \& Rialp-Criado 2007)

With globalization, the mortality rate of SMEs has increased significantly. They must adopt digital strategies and decisions to meet the challenges and survive. One of these challenges is the application of ICTs (Gamage, Kumara, Rajapaskshe, Ekanayake, Abeyrathne, Prasanna, \& Tayasundara 2019). By contrast, multinational companies have higher driving forces and lower barriers to Industry 4.0. The desire to increase control and allow real-time performance measurement is reason enough for SMEs to undertake digitization (Horváth \& Szabó 2019). These technologies on their own are not enough to benefit any company; they must be incorporated into daily activities and processes. They must also be considered within the company's sustainable technology strategy (Galo \& Cano-Pita 2017)

SMEs, by not investing in technology or in their own $\mathrm{R}+\mathrm{D}+\mathrm{I}$, can be left behind and stop being competitive. The industrial internet of things (IIoT) is impacting the business model of companies and the future of business. The IIoT refers to the interaction of industrial objects with information technologies, with companies, with their customers, and with their employees, thereby making tasks more productive (Jiwangkura, Sophatpathit, \& Chandrachai 2018).

The internet of things (IoT) describes the search for interaction between people and everyday objects through the internet. With the IoT, communication between objects and companies implies entry into the era of Industry 4.0 and has improved the availability of data in large companies, as well as the efficiency of their processes. But SMEs are a step behind, and also on the defensive, even though the IoT has tremendous potential to increase efficiency (König, Röglinger, \& Urbach 2019).

\section{DESCRIPTION OF THE PROBLEM}

In elevator maintenance service companies, as in other maintenance service industries, the biggest cause of failures in M\&A operations is the asymmetry of technical information on operational variables established between the pre-acquisition phase and the post-acquisition phase, which causes uncertainty and confusion in the integration stage and is not detected in operational DD. This information asymmetry stems from the different digital strategies that each party has developed and implemented, since most M\&A operations are carried out by large multinationals or investment funds that have the resources for powerful IT tools, while SMEs do not.

In the research conducted to find out more information about the causes of general M\&A operations failures, 
and this specific problem of information asymmetry, 155 articles have been reviewed, of which 86 have been selected from different disciplines using different keywords. Among these articles, we have also studied the different digital strategies that companies have, based on their size and resources, and how these different digital strategies can affect an M\&A operation between companies of different sizes, considering that small companies have not yet embraced Industry 4.0.

\section{WORKING HYPOTHESIS:}

Based on the reviewed and selected articles on M\&A processes, it can be said that there is a very extensive literature with many research studies over a number of decades, in which many conclusions have been reached and new lines of research recommended. However, it can also be concluded that there is still a lot of pending work that can contribute to the academic research and the successful practice of M\&A processes.

The pre-acquisition phase has also been written about, with much reference being made to ambiguity. Many failures are attributed to unresolved ambiguity in this phase prior to the signing of the contract.

This article focuses mainly on operational DD in the pre-acquisition phase. This phase is where the real operational information is often not detected. That is, it can be the source of an unresolved ambiguity that must be minimized or avoided. Technologies provided by Industry 4.0 must also be adopted in operational DD.

Each elevator has a lot to contribute with its daily, weekly, and monthly records of operations detailing all failures and behavior statistics. Thanks to the IoT, elevators have their own voice, which just has to be recorded and analyzed properly. Obtaining this information on operational variables directly allows us to understand from a technical point of view how the elevators are operating. If the elevators acquired are not in proper working condition due to poor service maintenance, the buyer may face moderate or serious additional profit and safety risks, which are unforeseen and undesired.

According to all of the above, we can propose the following hypothesis:

"Information and communication technologies (ICTs) can reduce the information asymmetry between E\&E maintenance companies that participate in an M\&A process, and consequently increase the success of the transaction."

Therefore, it can be stated that:

1. Information asymmetry that emerges in the integration phase reduces the success of M\&A processes.

On the one hand, in many cases the buyer is not able to determine the quality of the information provided by the seller and does not have all of the information. And on the other hand, although the seller generally has more information, he does not share it entirely.

George Akerlof (winner of the 2001 Nobel Prize in Economics), in his book The Market for Lemons, which is based on his research in markets with information asymmetry, defined the "junk market" model, where the second-hand product seller knows if his product is good or bad, while the buyer does not. Normally the buying party does not have the necessary information to know the negative characteristics of the seller's product, and this is a disadvantage that can be exploited by the party with more information (Akerlof 2001).

What variables are considered in M\&A processes in elevator maintenance companies?

The variables considered are the ratios of the financial statements of the company to be acquired, and the operational variables from the key performance indicators (hereinafter KPIs) of the balanced scorecard or dashboard of the seller, and their subsequent analysis for the study of synergies and profitability. An example of some important operational variables about maintenance service is given below in Figure 1:

\section{Hosted file}

image1.emf available at https://authorea.com/users/451711/articles/549902-mergersacquisitions-in-the-elevator-industry-the-use-of-icts-to-avoid-information-asymmetry 
Fig 1: Example of a dashboard developed by the authors with some relevant maintenance key performance indicators (KPIs).

These variables must be quantified, qualified, and compared with the average service levels of the industry in which the seller is operating, with the competitors, and also with the objectives established in the M\&A project, in order to have information and control once the transaction has been carried out.

2. Technology can reduce information asymmetry.

How can technology reduce information asymmetry? This can be achieved through correct data collection by the seller and its subsequent analysis and processing using big data tools. Information technology has gained greater importance in M\&A due to the globalization of digitization, and it creates value in the processes of a company. It supports the risk-free evaluation of the above-mentioned variables, and therefore can analyze the appropriate acquisition price (Stein, Zureck, \& Jäger 2018).

Nowadays, it is possible to store files and large volumes of data through remote access to software. This is called "cloud computing" and has become an essential tool for the development and growth of SMEs (Zabalza, Rio-Belver, Cilleruela, Gavechana, \& Gavilanes 2012). This tool makes it possible to store all the data for processing and treatment. As operations become more complex, technology and the people who provide and support IT are critical drivers for resolving ambiguities. ICTs are essential in the previous phase of integration (Larsen 2005).

ICTs enable communication through the IoT. In the US auto insurance market, for example, some insurance companies use technology to track driver behavior in order to apply the correct insurance premium. For example, a driver who takes risks will pay more than a conservative driver. The aim is therefore to monitor the driver's habits and behavior through a direct recording of information from the vehicle's IoT device. This monitoring through technology reduces information asymmetry and adverse selection (Chen \& Jiang 2019)

\section{ANALYSIS: ECONOMETRIC MODEL}

To support this theory regarding information asymmetry, an economic analysis was carried out regarding the impact in an M\&A process of the acquisition of elevators that are not in good working condition but were not identified as such during the operational DD process. Generally, around $5 \%$ of the portfolio generates more than $50 \%$ of breakdowns. The key is to identify all those elevators that are damaging the P\&L.

For this, we propose an econometric model that considers operational variables and how they affect each other, allowing us to make future predictions and estimates of the profitability and the return on investment. The proposed model tries to quantify the cost of acquiring an elevator in unsuitable working condition, and as a consequence, depending on the volume of these elevators acquired, how this can cause a non-return on investment.

Preventive maintenance is defined as maintenance carried out periodically according to national regulations and the execution program of each elevator maintenance company. Corrective maintenance is defined as maintenance that rectifies a fault and represents a cost for the company

Before we can apply the econometric model, we first need to define the average price values of the local and regional companies that can be acquired, both for preventive maintenance and annual repairs. The econometric model proposed can be applied to any market in any region, but we have taken the average values of the Spanish market as an example.

In the Spanish elevator market, we have to differentiate between two segments: the residential segment, composed of elevators installed in residential buildings, whose average type of installation is $450 \mathrm{~kg}$ (6 people), $1 \mathrm{~m} / \mathrm{s}$ of speed, and 8 stops; and the commercial segment, which is composed of both elevators and escalators in buildings such as hotels, shopping centers, offices, airports, and train or metro stations, and whose diversity of characteristics makes it impossible to determine an average type of elevators and escalators installed. For both segments there is a law in Spain that regulates periodic technical maintenance and rescue time. 
Therefore, and given the evidence that $99 \%$ of the portfolio of local and regional companies corresponds to the residential segment, we decided to carry out the econometric model study in the Spanish residential market. The premises we used are shown in Figure 2:

\section{Hosted file}

image2.emf available at https://authorea.com/users/451711/articles/549902-mergers-
acquisitions-in-the-elevator-industry-the-use-of-icts-to-avoid-information-asymmetry

Fig 2: Average values calculated from internal market studies and author's experience.

The profitability of an elevator maintenance contract is calculated based on the costs of preventive maintenance and corrective maintenance. These must be summarized and analyzed. Corrective maintenance costs are minimized when they are not required in the first place.

Figure 3 shows how the gross margin (GM) and the earnings before interest, taxes, depreciation, and amortization (EBITDA) of each maintenance contract are calculated, based on the sum of each elevator included in the contract. In Figure 3, an example is specified, based on the average market cost values of a local or regional company, which are lower than the average cost values of a multinational. Depending on each company and its market prices and operating costs, the GM and EBITDA may vary.

\section{Hosted file}

image3.emf available at https://authorea.com/users/451711/articles/549902-mergersacquisitions-in-the-elevator-industry-the-use-of-icts-to-avoid-information-asymmetry

Fig 3: Profit E⿱ loss (PESL) example for each elevator

The operational variable that measures the breakdowns of elevators is the "breakdown index," which refers to how many breakdowns occur per elevator over a given period of operation, normally a 12-month period. This KPI, which appears in Figure 1, is one of the most important parameters for calculating the profitability of a maintenance contract.

The ratio that should generally not be exceeded in multinational companies is $10 \%$, which comes from the maximum permissible number of breakdowns on a maintenance route (geographical group of elevators usually made up of 120 elevators maximum). Each route is serviced by a technician, who, generally, should always be the same.

In other words, a breakdown index of $10 \%$ on a route means that 12 breakdowns of different elevators (or the same elevator) occur throughout the year on that route.

Figure 3 shows that the uncontrolled cost that can damage the P\&L is the cost of corrective maintenance due to poorly performed preventive maintenance. The better the preventive maintenance, the lower the costs of corrective maintenance. The uncontrolled cost must include the opportunity cost of not performing preventive maintenance on other elevators in the daily route planning and the cost of overtime for the technician.

Following up on Figure 3, a normal preventive maintenance contract for one elevator that has a monthly income of $\backslash$ euro75 ( $\backslash$ euro900 per year) has a direct preventive maintenance cost of $\backslash$ euro46 per month ( $\backslash$ euro552 per year) and gives the company a GM of $\backslash$ euro348 (38.6\%), without breakdowns.

To obtain the EBITDA, the selling, general, and administrative expenses (SG\&A) of each individual company shall be applied.

\section{RESULTS}

Let's take as an example the premises of elevator 1 from Figure 1. Let's suppose 1, 2, and 3 breakdowns for elevator 1 this year, with 1 hour being spent to resolve each breakdown. We must also add 1 extra hour that the technician could have spent on preventive maintenance of the other elevators on his assigned route. 
Let's calculate the variation in profitability of the maintenance contract in all cases, assuming that the local company has an SG\&A of $15 \%$ :

\section{Hosted file}

image4.emf available at https://authorea.com/users/451711/articles/549902-mergersacquisitions-in-the-elevator-industry-the-use-of-icts-to-avoid-information-asymmetry

Fig 4: Comparative example of $P \mathscr{B} L$ with and without breakdowns.

The reason multinationals do not accept a breakdown index greater than $10 \%$ in their portfolio is because of the lack of profitability. It must also be considered that when the integration phase is completed, the hourly labor cost of a multinational company is higher than that of a local company. In an M\&A process, the impact of potential incoming orders of repairs, not included in the above calculations, is also very important for decision-making.

During the DD process there is a very high percentage of elevators that are not audited, and therefore their operating status is not really known, except for the information on breakdowns that the seller may provide. These elevators can represent an uncontrolled cost during the negotiation process and can damage the $\mathrm{P} \& \mathrm{~L}$ after integration, and even, most importantly, lead to an accident that destroys lives and company value.

\section{CONCLUSIONS}

The real operational variables could be obtained in real time with an IoT connection, through an interface device connected with the electronic board of the elevator, which incorporates a SIM card. This SIM card provides an internet connection to the interface, so that through the elevator's IoT connection, all the elevator's operational variables would be recorded for a certain period of time. This would allow proper analysis in order to take the correct decisions. It would also provide historical statistics that anticipate the present and future behavior of each elevator. These operational variables, together with the data of each maintenance contract extracted from the database, and the financial variables that would also be collected through the connection to the enterprise resource planning (ERPs), would form a pool of data that would subsequently be processed by big data tools, providing the buyer with accurate information.

The digital strategy applied by big multinational companies currently consists of a digital platform that can connect the elevator or escalator with technicians, passengers, and customers. The information obtained from the elevator or escalator's IoT device is used to predict preventive maintenance in order to reduce corrective maintenance. Each multinational company uses its own devices compatible with its own elevator and escalator brand to reduce its costs by predicting preventive maintenance. But when its products are maintained by local and regional companies, this digital strategy is not applied. There are universal IoT devices already on the market that can be connected to different brands. They can be used to record operational variables over a defined period of time in order to gauge the technical status of different brands of elevators.

With this information, the operational ambiguity of M\&A processes between elevator maintenance companies of different sizes and with different digital strategies would be resolved. Currently, a visual and technical check is carried out on a small sample (about $10 \%$ of the seller's portfolio) in the DD phase due to a lack of time and the high cost of resources. However, the use of this technology would make it possible to avoid using human resources, to steer clear of unprofitable large investments, and to create a $100 \%$ sample in some cases or a relevant portion in others, eliminating the risk of asymmetric information.

IoT devices will be the norm in the future and will assist humans in their daily routines. Souza, Carlson, Ramos, Loureiro, and Oliveira, in their article "Internet of Things Device Authentication via Electromagnetic Fingerprints" (2020), describe several scenarios where IoT devices can communicate and interoperate with any other interlocutor. One of these scenarios is that of vehicle-to-everything. Indeed, we can consider an elevator a vehicle.

What cannot be measured cannot be managed. 


\section{CONFLICT OF INTEREST STATEMENT}

Madrid, November $29^{\text {th }}, 2021$ I, Miguel Palacios Fernandez (PhD), Professor of Management at ESCP Business School, confirm that have contributed as co-author number 2 in the paper presented to Engineering Reports Journal, named "MERGERS \& ACQUISITIONS IN ELEVATOR INDUSTRY: THE ROLE OF ICTs TO AVOID INFORMATION ASYMMETRY " and that have not conflict of interest relevant to this article. My contribution has been as follows:

- Have made contributions to conception, acquisition data, and analysis and interpretation of data.

- Have been involved in the supervision and revision manuscript

- Given final approval of the final version to be published.

Therefore, I state I have participated sufficiently and take responsibility for appropriate portions of the content and agreed to be accountable for all aspects of the work, ensuring that questions related to the accuracy or integrity of any part of the work are appropriately investigated and resolved.

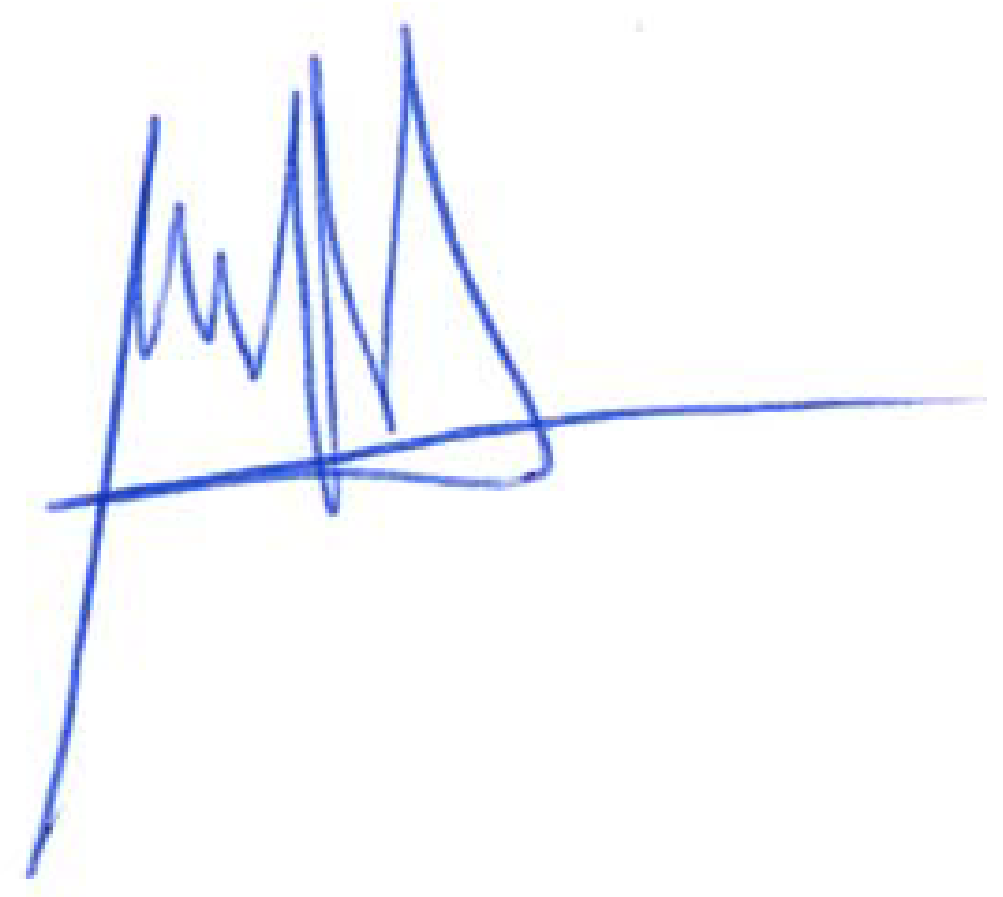

Dr. Miguel Palacios Fernandez

I, Ricardo Palomo Zurdo (PhD), Dean and Professor of Finance in School of Business and Economics at Universidad CEU San Pablo, confirm that have contributed as co-author number 3 in the paper presented to Engineering Reports Journal, named "MERGERS \& ACQUISITIONS IN ELEVATOR INDUSTRY: THE ROLE OF ICTs TO AVOID INFORMATION ASYMMETRY " and that have not conflict of interest relevant to this article.

My contribution has been as follows:

- Have made contributions to conception and analysis and interpretation of data.

- Have been involved in the supervision and revision manuscript

- Given final approval of the final version to be published. 
Therefore, I state I have participated sufficiently and take responsibility for appropriate portions of the content and agreed to be accountable for all aspects of the work, ensuring that questions related to the accuracy or integrity of any part of the work are appropriately investigated and resolved.



Dr. Ricardo Palomo Zurdo

Madrid, $27^{\text {th }}$ November, 2021

BIBLIOGRAPHIC REFERENCES:

Afzal, W., Roland, D., \& Mohammad Nasser Al-Squri. (2009). Information asymmetry and product valuation: An exploratory study. Journal of Information Science, 35 (2), 192-203. 10.1177/0165551508097091

Akerlof, G. (2001). The market for Lemons. S.I.,s.n.

Boeh, K.K. (2011). Contracting Costs and Information Asymmetry Reduction in Cross-Border M\&A. WileyBlackwell: Journal of Management Studies .

Brueller, N. N., \& Capron, L. (2021). Acquisitions of startups by incumbents: The 3 cs of co-specialization from startup inception to post-merger integration. California Management Review, 812562199650. $10.1177 / 0008125621996502$

Calipha, R., Tarba, S., \& Brock, D.Mergers and acquisitions: A review of phases, motives, and success factors. Emerald Group Publishing. 10.1108/s1479-361x(2010)0000009004

Cartwright, S., \& Schoenberg, R.30 years of mergers and acquisitions research: Recent advances and future opportunities

Chen, Y., \& Jiang, B. (2019). Effects of monitoring technology on the insurance market. Production and Operations Management, 28 (8), 1957-1971. 10.1111/poms.13023

Correani, A., Massis, A., Frattini, F., Messeni, A., Natalicchio, A. (2020) Implementing a digital strategy: Learning from the experience of three digital transformation projects. California Management Review Journal . 10.1177/0008125620934864

Cuypers, I. R. P., Cuypers, Y. K., \& Martin, X. (2017). When the target may know better: Effects of experience and information asymmetries on value from mergers and acquisitions. Strategic Management Journal, 38 (3), 609-625. 10.1002/smj.2502

Dierickx, I.Information asvmmetries how not to 'buy a lemon' in negotiating merges and acquisitions

Galo E. Cano-Pita (2017). "Las TIC en la empresa: Evolución de la Tecnología y cambio estructural en la organización." Revista científica Dominio de las Ciencias 
Gamage, N., Kumara, S., , E., , A., , P., Rajapakshe, J., Kumara, S., Gamage, N., Ekanayake, E., Abeyrathne, G., Prasanna, R., Jayasundara, J., \& Rajapakshe, P. (2019). Global challenges and survival strategies of the SMEs in the era of economic globalization: A systematic review.

Munich personal RePEc archive

Garcia-Canal, E,; Rialp-Criado, A; Rialp-Criado,J. (2007). Tecnologías de la Información y Comunicación y crecimiento de la empresa". ICE Nuevos productos, nuevos mercdaos y nuevas formas de internacionalización

Horváth, D., \& Szabó, R. Z. (2019). Driving forces and barriers of industry 4.0: Do multinational and small and medium-sized companies have equal opportunities? Technological Forecasting Eamp; Social Change, 146 , 119-132. 10.1016/j.techfore.2019.05.021

Jiwangkura, S., Sophatsathit, P., \& Chandrachai, A.Industrial internet of things implementation strategies with HCI for SME adoption. 10.5875/ausmt.v10i1.2108

König, U., Röglinger, M., \& Urbach, N. (2019, Dec). Industrie 4.0 in kleinen und mittleren Unternehmen - Welche Potenziale lassen sich mit smarten Geräten in der Produktion heben? HMD Praxis der Wirtschaftsinformatik, 56 , 1233-1249. doi:10.1365/s40702-019-00567-w Retrieved from https://search.proquest.com/docview/2315545895

Larsen, M. H., (2005). ICT integration in an M\&A process.

Conference Paper (200505-01).

Nayyar, P. R. (1990). Information asymmetries: A source of competitive advantage for diversified service firms. Strategic Management Journal Vol.11,513-519

Pirola, F., Cimini, C., \& Pinto, R. (2019). Digital readiness assessment of italian SMEs: A case-study research. Journal of Manufacturing Technology Management, 31 (5), 1045-1083. 10.1108/JMTM-09-2018-0305

Reuer, J. J., \& Ragozzino, R. (2008). Adverse selection and M\&A design: The roles of alliances and IPOs. Journal of Economic Behavior \& Organization, 66 (2), 195-212. 10.1016/j.jebo.2006.04.003

Reuer, J., \& Akerlof, G.Avoiding lemons in M\&A deals . Working paper view project strategic logistics partnerships: Contracts and performance view project

Souza A, Carlson I, Ramos HS, Loureiro AA, Oliveira LB. Internet of Things device authentication via electromagnetic fingerprints.Engineering Reports . 2020;2:e12226. https://doi.org/10.1002/eng2.12226

Stein, D., Zureck, A., \& Jäger, T. (2018). A call to theorize digital information technology due diligence: analysis of research gaps for the subject of information technology due diligence in mergers and acquisitions. European Financial Systems 2018-XV Conferencia Cientifica Internacional 2018

Sundberg, B., Tan, Z., Baublits, T., Lee, H, , Stanis, G., Tanriverdi, H. (2006). A Framework for Conducting IT Due Diligence in Mergers and Acquisitions. ISACA Journal, vol. 6, 2006, www.isaca.org/archives 25 National Institute of Standards and Technology, $M$

Trichterborn, A., Zu Knyphausen-Aufseß, D., \& Schweizer, L. (2016). How to improve acquisition performance: The role of a dedicated M\&A function, M\&A learning process, and M\&A capability. Strategic Management Journal, 37 (4), 763-773. 10.1002/smj.2364

Zabalza, J., Rio-Belver, R., Cilleruelo, E., Garechana, G., \& Gavilanes, J.(2012) Benefits related to cloud computing in the SMEs 